\title{
A SIMPLE CONTROL STOPCOCK FOR GAS ANALYSIS APPARATUS
}

\author{
By Martin Shepherd
}

\section{ABSTRACT}

This note describes a simple control stopcock for gas analysis apparatus. The control permits pressure balance to be obtained easily, quickly, and with high accuracy. Diffusion errors are eliminated without danger of emptying the manometer. The accidental surge of pipette reagents into the train is prevented. Difficult combustions of heavy hydrocarbons may be made without the deposition of carbon. The technique of operation and actual means of construction of the stopcock are described.

\section{CONTENTS}

I. A technique for obtaining pressure balance in gas-analysis units_-_II. The control stopcock III. Construction of the control stopcock

\section{A TECHNIQUE FOR OBTAINING PRESSURE BALANCE IN GAS ANALYSIS UNITS}

The technique usually employed to obtain a pressure balance in the ordinary gas analysis apparatus consists of a vertical movement of the levelling bulb which supplies the confining fluid to the burette. This adjustment is made by hand or by some gear system. The first is inaccurate and the second cumbersome.

A simple and accurate technique, which has been used for many years at the Bureau of Standards, may be described with reference to the assembly drawing of the gas-analysis unit shown in Figure 1. The levelling bulb $L$ is connected to the burette $B$ through the stopcock 3 . The pressure balance is obtained simultaneously within the burette and distributing train $T$ by adjusting the tee cock 1 to connect the train on both sides with the manometer $M$ interposed between the burette and the compensator $C$. The correct pressure balance is indicated in $M$ by a platinum point placed in the arm adjacent to the compensator. When a rising mercury meniscus makes contact with this point, an electric circuit is closed, lighting a 2-volt lamp. This assembly and method of indicating the point of balance are well known and have been previously described.

Pressure balance in such a unit may be easily adjusted as follows: With stopcock 2 closed and stopcock 3 opened, the pressure in the burette is roughly adjusted to about $1 \mathrm{~cm}$ less than atmospheric with the levelling bulb held in the hand. This will prevent emptying the mercury from the manometer. The leveling bulb is then placed on the split ring $R$ and the stopcock 3 is slowly opened to permit the entrance of the confining fluid to the burette, which gradually increases the pressure until the manometer indicates this to be equal to the pressure within the compensator. Stopcock 3 is instantly closed and the burette reading may be taken.

The only objection offered to this method lies in the difficulty of only slightly opening the lower burette cock. This must be opened 
very slowly, and the operation is somewhat troublesome to master. It is frequently necessary to repeat the operation several times before a successful adjustment is attained. A further complication may arise from the presence of a slight excess of lubricant around the bore or outlet of the cock, which oftens dams the flow of the confining fluid until the cock has been opened too far.

\section{THE CONTROL STOPCOCK}

The stopcock shown in Figure 2 completely eliminates such difficulties. The plug of this cock has two bores, one of which has the
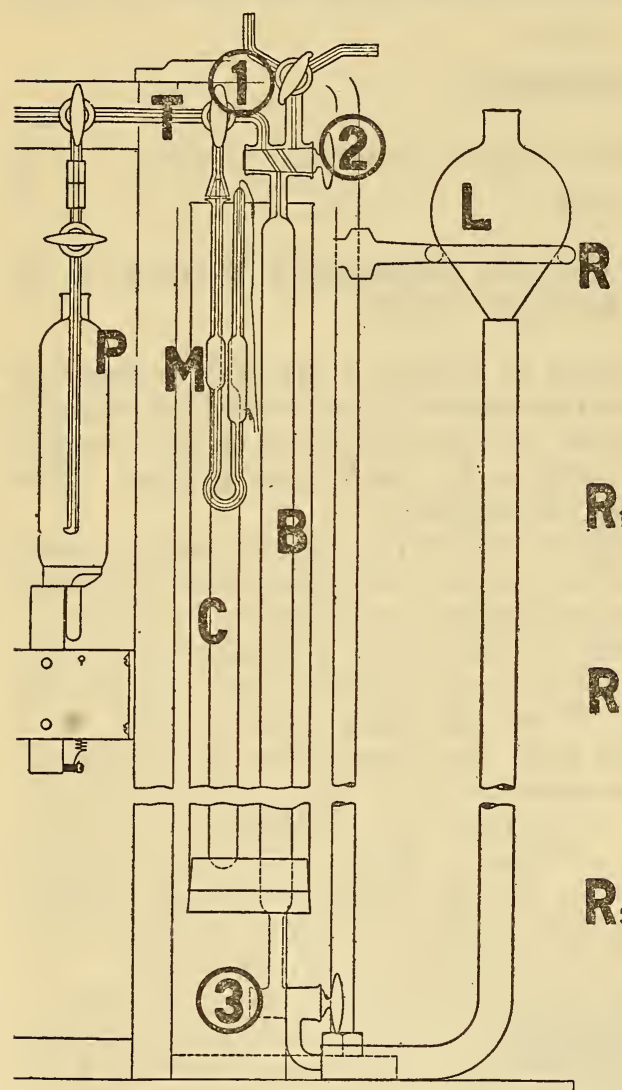

Figure 1.-Partial assembly of gas analysis unit fine constriction shown. Rough adjustments may be made through the open bore, following which a $90^{\circ}$ turn of the plug admits an extremely slow flow of mercury to the burette. The mercury can be quickly raised to within a millimeter from the contact point of the manometer by partially opening the full bore. A turn of the key through $90^{\circ}$ opens the constricted bore and com-

2 pletes the contact, the mercury rising so slowly that the eye is unable to determine when contact has been mado until the lamp reveals it.

Three additional split rings, 2. whose positions are at the points $R_{1}, R_{2}$, and $R_{3}$, indicated in Figure 1 are placed at even intervals. The position of the lower ring is such that when the leveling bulb

$P_{3}$ is resting thereon and stopcock 3 is opened the mercury level within the burettestands just below the $100 \mathrm{ml}$ etch mark. Such an arrangement permits the operator to maintain a roughly equal head of mercury on the burette when making pressure adjustments.

This will cause a fairly uniform rate of flow of mercury in the manometer toward the contact point, a result which is quite desirable. The time lag in closing cock 3 after contact has been made results in no measureable error whatsoever, because of the uniform and very slow rate of flow of the manometer mercury.

The precision with which pressure balance can be obtained by this method is only one of the advantages accruing from the use of 
the control cock. There are several other benefits which should be considered.

It is desirable to displace the gas confined in the manometer arm connected to the distributing train before passage to any of the pipettes of the apparatus. Any part of the gas sample which has diffused into this arm of the manometer may be drawn into the burette by placing the leveling bulb on the lower split ring and opening stopcock 3 . The thread of mercury in the capillary lead to stopcock 1 can be safely controlled by using the constricted bore of the control cock. There is thus no danger of emptying the manometer mercury in to the train.

Check valves placed in the capillaries leading from the absorption pipettes to the train have been found to be generally unsatisfactory. When no automatic check is provided there is ever present the possibility of drawing a reagent from the pipettes into the train. The control cock eliminates this danger and makes it possible to accurately bring the reagent from the pipette to an etch mark on the capillary lead. Furthermore, if one of the bubbling types of pipette

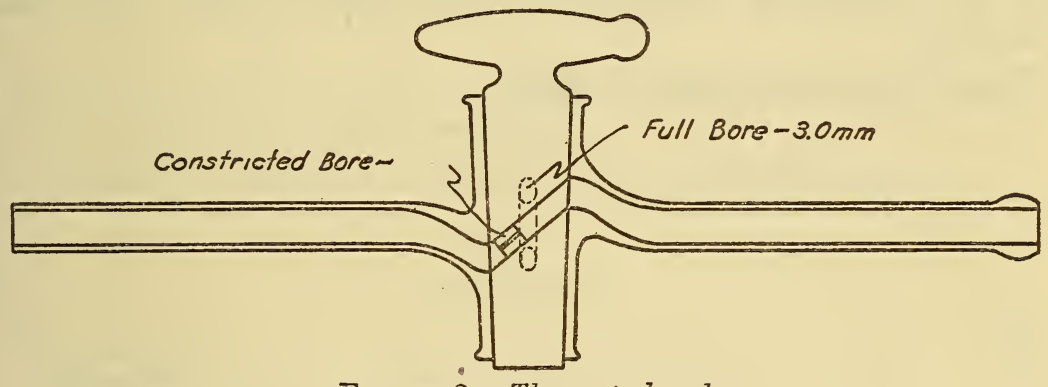

FigURE 2.-The control cock

is used, it occasionally happens that the diagonal bore of its stopcock may become temporarily plugged with lubricant. When this occurs the reagent is instantly drawn into the train through the capillary inlet of the pipette, even though the stopcock is turned to the correct position to withdraw gas from the pipette. To prevent such an accident the control cock may be turned to the constricted bore when first the gas is to be withdrawn. If the reagent does not slowly rise in the capillary inlet of the pipette, the cock may be immediately opened to the full bore.

It is difficult to obtain a quantitative combustion of acetylene, ethylene, ethane, propane, and heavy hydrocarbons in an atmosphere of oxygen over a heated platinum spiral. Unless the rate of flow of the hydrocarbon into the combustion pipette is very slow, deposition of carbon occurs. During some recent analyses of propaneethane mixtures it was found impossible to prevent the deposition of carbon unless the gas was admitted at the slow rate insured by use of the control cock.

\section{CONSTRUCTION OF THE CONTROL STOPCOCK}

This stopcock may be made in several ways. The glass blower may seal a No. 38 (B. and S. gage) copper wire into the solid key and along the axis of one bore. The key is then drilled out from opposite 
sides, leaving an undrilled portion of 2 to $3 \mathrm{~mm}$ thickness just off the center of the key. Nitric acid is used to remove the copper wire remaining in the undrilled portion.

Another method is as follows: Draw down an ordinary $7-\mathrm{mm}$ glass tube so that one end is sealed shut and the outside diameter of the drawn-out portion of the tube snugly fits the ordinary 3 or $4 \mathrm{~mm}$ bore of the stopcock. Cut 2 or $3 \mathrm{~mm}$ segments from this tube beginning at the point where the tube first opens to a fine capillary. Select a segment of the proper bore and cement this within the ordinary bore of the stopcock plug. DeKotinsky cement has been found suitable for this purpose.

It is evident that the fine constriction must be placed away from the outside surface of the stopcock plug. When this is done no trouble results from plugging by the stopcock lubricant.

A possible modification of the control cock would be to provide the burette with two lower stopcocks terminating at both ends in a $Y$ junction. A section of very fine capillary tubing could then be sealed into the lead of one stopcock. Such an arrangement, however, does not possess the convenience of the single control cock here described.

Washington, September 4, 1929. 